\title{
Pulmonary Mycobacterium kansasii infection successfully treated with a regimen containing erythromycin
}

\author{
P J GUEST, M G BRITTON, H C GRUNDY, M D YATES \\ From St Peter's Hospital, Chertsey, Surrey, and the Regional Centre for Tuberculosis Bacteriology, Public \\ Health Laboratory, Dulwich Hospital, London
}

\begin{abstract}
We report a case in which erythromycin was used in place of rifampicin after a severe reaction to the latter in the treatment of pulmonary Mycobacterium kansasii infection.
\end{abstract}

\section{Case report}

An 83 year old man presented with physical deterioration, weight loss, and self neglect. There was no history of cough or haemoptysis, or of previous tuberculosis. His weight was $42 \cdot 8$ $\mathrm{kg}$ and he had an intermittent low grade pyrexia. Examination otherwise showed nothing remarkable. Investigations revealed normochromic, normocytic anaemia (haemoglobin concentration $11.1 \mathrm{~g} / \mathrm{dl}$ ) and an erythrocyte sedimentation rate (ESR) of $103 \mathrm{~mm}$ in the first hour. Chest radiography showed ill defined soft tissue shadowing with cavitation affecting both upper zones, particularly on the left, and shadowing at the left base. Mantoux testing gave a negative result. Fibreoptic bronchoscopic washings and brushings contained moderate numbers of acid fast bacilli subsequently identified as $M$ kansasii. The organism was sensitive to rifampicin, ethambutol, erythromycin, and co-trimoxazole but resistant to streptomycin and isoniazid.

Meanwhile anti-tuberculosis treatment had been started with rifampicin $(450 \mathrm{mg})$, isoniazid $(300 \mathrm{mg}$ ), and ethambutol $(600 \mathrm{mg})$ daily. After two weeks' treatment he developed a hepatic reaction with vomiting, jaundice, and deranged liver function. Treatment was therefore curtailed. Reintroduction of rifampicin two weeks later, when liver function was normal, precipitated a cutaneous reaction. Treatment was therefore continued with isoniazid, ethambutol, and pyridoxine. Two weeks later, when the organism had been identified and the sensitivities were known, erythromycin stearate (500 $\mathrm{mg}$ thrice daily) was added.

Treatment was continued for a further 11 months, which resulted in clinical improvement, as evidenced by weight gain $(48.6 \mathrm{~kg}$ ), resolution of the anaemia (haemoglobin concentration $13.3 \mathrm{~g} / \mathrm{dl}$ ), and a fall in the ESR to $15 \mathrm{~mm}$ in the first hour. The chest radiograph showed considerable hardening of the inflammatory shadowing and total clearing of the changes at the left base, leaving some residual thin walled cavities at both apices. Repeat bronchoscopy was not felt to be warranted.

The patient remained well until six months after finishing

Address for reprint requests: Dr M G Britton, St Peter's Hospital, Chertsey, Surrey KT16 0PZ. treatment, when he died suddenly at home, probably from septicaemia secondary to an acute chest infection.

\section{Discussion}

$M$ kansasii is an opportunist organism which frequently infects previously damaged lungs. Both the relative and the absolute incidences of opportunistic mycobacterial infections appear to increase in areas where tuberculosis is in decline.' The diagnosis is made by repeated isolation from sputum in appropriate clinical settings, or by invasive techniques such as bronchoscopy.

The treatment of $M$ kansasii infection has been reviewed. ${ }^{2}$ Before the advent of rifampicin results of chemotherapy were poor and surgical resection was common. $M$ kansasii is almost invariably sensitive to rifampicin and its use in combination with other antituberculosis drugs has been very effective. Previously drugs have been given for 18-24 months, but short course (that is, 12 months) treatment has been advocated. ${ }^{3}$ Acquired resistance to rifampicin by $M$ kansasii has been reported. ${ }^{4}$

Drugs not normally considered in the treatment of tuberculosis have been considered or used in opportunist mycobacterial infections. These include amikacin, doxycycline, and sulphamethoxazole. Erythromycin has been shown to be active in vitro against atypical mycobacteria, ${ }^{5}$ including $M$ kansasii. It has been used clinically for disseminated 3 Mycobacterum chelone infections, ${ }^{6}$ and for cold abscesses $\phi$ resulting from severe BCG vaccination reactions. ${ }^{7-9}$ Singh suggested its use for $M$ kansasii septic arthritis. ${ }^{10}$

Although erythromycin is not normally used for long term treatment, it is likely to be less toxic than the standard $D$ antituberculosis drugs. Our experience suggests that there may be a useful role for erythromycin in the treatment of $M N$ kansasii infection, which might be explored further.

We wish to thank Dr A Beeson for allowing us to report on one of his patients.

\section{References}

1 Yates MD, Grange JM, Collins $\mathrm{CH}$. The nature of mycobacterial disease in South East England, 1977-84. J Epidemiol Commun Health 1986;40:295-300.

2 Grange JM, Yates MD. Infections caused by opportunist mycobacteria: a review. J R Soc Med 1986;79:226-9.

3 Schranfragel DE, Leech JA, Schranfragel MN, Poliak B. Short course chemotherapy for mycobacteriosis kansasii. Can Med Ass $J$ 1984;130:34-8. 
4 Davidson P, Waggoner R. Acquired resistance to rifampicin by Mycobacterium kansasii.

5 Mdavi $A$, Weinstein $L$. In vitro activity of erythromycin against atypical mycobacteria. J Infect Dis 1971;123:216-9.

6 Azadian BS, Beck A, Curtis JR, et al. Disseminated infection with Mycobacterium chelonei in a haemodialysis patient. Tubercule 1981;62:281-4.

7 Power J, Steart I, Ross J. Erythromycin in the management of troublesome BCG lesions. Br J Dis Chest 1984;78:192-4.

8 Singh G, Singh M. Erythromycin for BCG cold abscess. Lancet 1984;ii:979.

9 Hanley SP, Gumb J, MacFarlane JT. Comparison of erythromycin and isoniazid in treatment of adverse reactions to BCG vaccination. Br Med J 1985;290:970.

10 Singh G. Treatment of septic arthritis due to Mycobacterium kansasii. Br Med J 1985;290:857. 